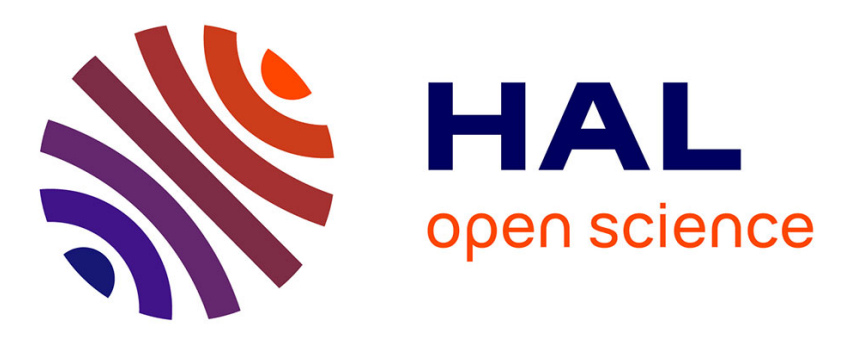

\title{
Non-native perception of final boundary tones in French interrogatives
}

Fabian Santiago, Paolo Mairano, Elisabeth Delais-Roussarie

\section{To cite this version:}

Fabian Santiago, Paolo Mairano, Elisabeth Delais-Roussarie. Non-native perception of final boundary tones in French interrogatives. Campbell, N. and D. Hirst. Speech Prosody $2014-7$ th International Conference on Speech Prosody, May 2014, Dublin, Ireland. pp.563-567, 2014, Non-native perception of final boundary tones in French interrogatives. Proceedings of Speech Prosody 2014. halshs-01428563

\section{HAL Id: halshs-01428563 \\ https://shs.hal.science/halshs-01428563}

Submitted on 20 Mar 2018

HAL is a multi-disciplinary open access archive for the deposit and dissemination of scientific research documents, whether they are published or not. The documents may come from teaching and research institutions in France or abroad, or from public or private research centers.
L'archive ouverte pluridisciplinaire HAL, est destinée au dépôt et à la diffusion de documents scientifiques de niveau recherche, publiés ou non, émanant des établissements d'enseignement et de recherche français ou étrangers, des laboratoires publics ou privés. 


\title{
Non-native perception of final boundary tones in French interrogatives
}

\author{
Fabián Santiago $^{1}$, Paolo Mairano $^{2}$, Elisabeth Delais-Roussarie ${ }^{1}$ \\ ${ }^{1}$ UMR 7110-Laboratoire de Linguistique Formelle, Université Paris Diderot, France \\ ${ }^{2}$ University of Turin, Italy \\ rotinet@hotmail.com, paolomairano@gmail.com, elisabeth.roussarie@wanadoo.fr
}

\begin{abstract}
The aim of the paper is to present the results of a perception experiment in which native and non-native listeners were asked to rate the appropriateness of resynthesized questions varying in respect to two aspects: their morphosyntactic structure (presence/absence of an interrogative marker) and the form of their final intonational contour (falling, rising and extra-rising). The goal of the experiment was to examine how non-native listeners of French did perceive the extra-rising final contour that was observed in learners' productions. Do they consider it as appropriate even if it did not occur often in the native speakers' productions? By and large, the results of the experiment show that native listeners preferred rising contours over falling ones in all question types, whereas nonnative listeners rated the extra rising contours higher than French natives in stimuli having a morphosyntactic structure that differs from the one used in their L1. These results may suggest that rising contours represent a default tonal form associated with the interrogative modality not only at the beginning of the L2 acquisition process, but also in speakers' mental representation, irrespective of their L1.
\end{abstract}

Index Terms: L2 intonation, L2 acquisition,

\section{Introduction}

It is often assumed that the prosodic patterns observed in the productions of second/foreign language learners are mainly influenced by their L1 prosodic structure. L1 transfer is thus considered as playing a crucial role (see [1] and [2] for an overview). However, several studies have shown that, in some cases, the L1 transfer cannot be invoked to account for some observed patterns. Other factors have thus to be taken into consideration to explain singular prosodic forms of the L2 learners' grammar [3]. In previous work, for instance, we have shown that Mexican Spanish learners of L2 French produce systematically an extra-rising contour at the end of information-seeking questions (see [4] and [5]). Even if the occurrence of this form can be considered as resulting from a L1 transfer in yes-no questions, it is not possible in the case of wh-questions (see section 2.3 for more information). The overuse of this contour could thus be seen as resulting from the L2 acquisition process itself. Such explanation may have consequences on the perception, this form being not necessarily considered as accurate in French. Do the learners consider it as appropriate at various early stages of the L2 acquisition process, even if the form is not often heard?

This article is organized as follows. In section 2, we provide background information on the prosody of French and Spanish interrogatives. Section 3 focuses on the experimental protocol of the perception experiment. In section 4, we present the results obtained. Finally, the implications of the results for the theories focusing on the acquisition of intonation in an L2 are summarized in the last section.

\section{Intonation in questions in French and Spanish: L1 vs. L2}

In descriptions of French and Spanish intonation, yes-no questions are usually characterized by ending with a rising contours $(\mathrm{H} \%)$, while wh-questions are associated with falling contours (L\%). Nevertheless, different tonal configurations can be observed in both interrogative sentence types: falling tones could appear in French yes-no questions when the lexical content and/or the morphosyntactic structure already indicates the modality of the utterance, whereas rising patterns can appear in both Spanish and French wh-questions. In the following sub-sections, we summarize the distribution of these contours with respect to the morphosyntactic structure and to the canonical patterns usually reported in the literature.

\subsection{The intonation of yes-no questions}

Information-seeking yes-no questions do differ in Spanish and French with respect to their morphosyntactic forms. In Spanish yes-no questions, two morphosyntactic structures are observed with nominal subjects: either the subject precedes the verb as in an assertive sentence (1), or the subject and the verb are inverted as in (2). In contrast, French yes-no questions can be produced with a larger range of linguistic forms: in addition to the declarative structure (3), a subject-verb inversion can occur, be the subject nominal or pronominal (4), and the interrogative marker 'est-ce que' can be inserted at the beginning of the utterance (5).
(1) ¿Juan estudia?
'Juan studies?'
(2) ¿Estudia Juan?
'Studies Juan?'
(3) Vous étudiez ?
'You study?'
(4) a. Étudiez-vous?
'Study you?'
b. Pierre étudie-t-il?
'Does Pierre study?'
(5) Est-ce que vous étudiez?
'You study?'

As for intonational patterns, Mexican Spanish yes-no questions are produced with a rising contour regardless of the syntactic structure: a final rise, which covers approximately an octave (12 semitones), is realized from the penultimate syllable to the end of the utterance, and the final pitch target generally reaches the top of the speakers' range. This tonal pattern is perceived as an extra high rising pitch movement, and is more frequently observed in Mexico City Spanish (see [6], [7], and [8]).

In contrast, French speakers may use a larger inventory of melodic movements at the end of questions without changing the meaning of the utterance. In yes-no declarative questions (as in (3)), a rising pitch movement realized on the last syllable of utterance (or on the last accentual phrase) and covering in average 8 semitones is usually observed (see [9] and [10] among others). By contrast, in yes-no questions in which the interrogative modality (as in (4) or (5)) is expressed by a marker or the morphosyntactic form, the final contour can 
be either falling $\mathrm{L} \%$ or rising $\mathrm{H} \%$, the $\mathrm{H} \%$ vs. $\mathrm{L} \%$ contrast being in a certain extent neutralized.

In the remaining of the paper, the differences between the various tonal configurations will be noted as follows: the label $\mathrm{H} \%$ is used for rising contours, the label $\mathrm{HH} \%$ for extra rising one, and the label $\mathrm{L} \%$ for falling one (see the representation in Fig. 1 in section 2.3).

\subsection{The intonation of Wh-questions}

The morphosyntax of wh-questions differs in Spanish and French with respect to the possible positions of the interrogative expression. Information-seeking wh-questions are always constructed with the interrogative word in utterance-initial position in Spanish (6a). By contrast, it is possible in French to utter a wh-question with the whexpression in sentence-initial position (wh-'fronted') as in (6b), or with the expression in the position where the answered complement should occur (wh-'in-situ') as in (7):

$$
\begin{aligned}
& \text { (6) a. ¿Qué estudias? 'What study (you)?' } \\
& \text { b. Qu'est-ce que tu étudies? } \\
& \text { (7) c. Tu étudies quoi? }
\end{aligned}
$$

A cross-linguistic comparison of the tonal configurations occurring at the end of wh-questions in both French and Spanish shows that there are more similarities between both languages than in the case of yes-no questions: the final contour is often falling L\% (see [6], [7], [8], [10], [11], [12] and [13]), but rising one could also be used. Note also that the extra rising contour $\mathrm{HH} \%$ is almost inexistent in natives' oral productions in both Spanish and French in this question type (see [5], [8] and [10] among others).

\subsection{Intonation of interrogatives in L2 French}

In previous studies dedicated to the intonation of questions in L2 French by Mexican Spanish speakers, it has been shown that learners often use the extra rising contours $\mathrm{HH} \%$ in yes-no and wh-questions (se [4], [5]). The fig. 1 gives a schematic representation of the contours observed at the end of the two question types -'Do you study?' for the yes-no question, and 'Where are you going?' for the wh-question- in the productions of Native French speakers (FL1), Spanish learners of French (FL2) and natives Spanish (SL1). The horizontal

\begin{tabular}{|c|c|c|c|}
\hline $\begin{array}{l}\text { Syntactic } \\
\text { Structure }\end{array}$ & FL1 & FL2 & SL1 \\
\hline $\begin{array}{l}\text { yes-no } \\
\text { question }\end{array}$ & $\begin{array}{r}\text { Tu étudies ? } \\
\mathrm{H} \%\end{array}$ & $\begin{array}{r}\text { Tu étudies? } \\
\text { HH } \%\end{array}$ & $\begin{array}{r}\text { ¿Estudias? } \\
\text { I } \\
\mathrm{HH} \%\end{array}$ \\
\hline wh-question & $\begin{array}{r}\text { Où vas-tu } ? \\
\mathrm{~L} \%\end{array}$ & $\begin{array}{c}\text { Où vas tu? } \\
\text { HH } \%\end{array}$ & $\begin{array}{r}\text { ¿A dónde vas? } \\
1 \\
\mathrm{~L} \%\end{array}$ \\
\hline
\end{tabular}
dotted line in the figure represents the top of the speaker's range.

Figure 1: Stylization of the three final boundary tones.

From the data analyzed, [4] and [5] argued that the extrarising tonal form $\mathrm{HH} \%$ could be attributed to an $\mathrm{L} 1$ transfer in the cases of yes-no questions, since this form is quite common in the Mexican Spanish variety. Yet, for wh-questions, an analysis in terms of transfer cannot be argued for, since this question type is generally produced with a falling contour L\% in Spanish. Hence, different explanations have to be found to account for the occurrence of this pattern. The first proposal we could argue for is that at an early stage of the L2 acquisition process speakers have at their disposal a reduced inventory of tonal forms, in which rising tunes (be they $\mathrm{H} \%$ or $\mathrm{HH} \%$ ) are employed by default for expressing any kind of interrogative modality (see also [3]). The second one relies on a certain difficulty for learners to distinguish the difference between rising and extra-rising contours, since this difference is more phonetic in nature. The third one, which will not really be investigated here, assumes that learners, by being less confident, express linguistic insecurity about their performances by using such a form. The extra rising contour $\mathrm{HH} \%$ would thus encode a lack of confidence in the L2 (see also [14]).

\section{Perception experiment}

In order to get some information on what could motivate the occurrence of the extra-rising contours, and to evaluate which of the first two hypotheses mentioned in section 2.3 is the most relevant, we set up a perception test. The learners had to evaluate which of the various contours (between $\mathrm{HH} \%, \mathrm{H} \%$ and $\mathrm{L} \%$ ) is the more appropriate at the end of the different question types. If the use of extra rising contours at the end of questions is related to the speakers' L1 or to the acquisition process itself, this contour should be significantly perceived as appropriate, at least by learners at an early stage, in all settings. However, the more advanced learners should not rate extra-rising contours as accurate as beginners. If the difference between the two forms is phonetic in nature, the choice of one contour over the other should not necessarily be significant, at least for the learners. Results obtained in this experiment should thus help us to evaluate whether the preference for $\mathrm{HH} \%$ observed in learners' oral productions is related to the L2 acquisition process, or not.

In addition, the other assumptions can be partly verified by referring to the use of the forms. Indeed, native and non-native listeners should display differences according to their L1 in the way of evaluating the different final boundary tones in relation to the morphosyntactic structure of the question. As final rises are usually $\mathrm{HH} \%$ for Mexican native speakers (be they learners of French or not), they should rate $\mathrm{HH} \%$ better than $\mathrm{H} \%$ in yes-no declarative questions, whereas French native participants should rate $\mathrm{H} \%$ better than $\mathrm{HH} \%$. In the case of yes-no questions, in which the interrogative modality is signaled by the morphosyntactic forms (as in (4) and (5)) as well as in wh-questions (as (6) and (7)), native listeners show a preference for $\mathrm{H} \%$ and $\mathrm{L} \%$ over $\mathrm{HH} \%$, which has rarely been observed in the data (see [4] and [5]). In the case of the L2 learners, we could expect to obtain the same results as for SL1 listeners, despite the fact that they use mostly the $\mathrm{HH} \%$ contour. This expectation is based on the hypothesis that perception in an L2 is influenced by the participants' L1.

\subsection{Experimental procedures and materials}

Three classes of listeners were asked to participate to the perception test: native French speakers, native Mexican speakers, and Mexican learners of L2 French. The stimuli consisted of 96 resynthesized information-seeking questions (66 in French and 30 in Spanish). They were classified in four sets: (i) yes-no questions without any interrogative marker in 
declarative form (as in (1) and (3)); (ii) yes-no questions with a syntactic marker indicating the modality of the utterance (French only, as in (5)); (iii) wh- 'fronted' questions (as in (6)); and (iv) wh-'in-situ' questions (French only, as in (7)). The questions contained in set (i) displayed two different final rising contours: $\mathrm{HH} \%$ and $\mathrm{H} \%$. Interrogatives in sets (ii), (iii) and (iv) had three different final tones: $\mathrm{HH} \%, \mathrm{H} \%$ and $\mathrm{L} \%$.

Two native phoneticians (one for either language) recorded stimuli at the Laboratory of Linguistics from the University of Paris Diderot. At a first step, we obtained a stylization of the entire F0 trace associated with the various questions. At a second one, the final contours were manipulated in Praat in order to obtain perfectly coherent realizations. The manipulation was achieved along the following guidelines:

1. The $\mathrm{HH} \%$ contour was obtained from the $\mathrm{H} \%$ final rise in the natural stimuli, which were manipulated so that the rise would span $>11$ semitones.

2. The $\mathrm{H} \%$ contour was also manipulated with Praat in order to enhance comparability between stimuli (we wanted to avoid mixing natural and manipulated stimuli): rises of 8 semitones were decreased to 6 , while rises of 6 semitones were increased to 8 st.

3. The L\% contours were extracted from phoneticians' realizations and manipulated into low flat plateaus.

In figure 2, we illustrate the manipulations that were carried out in the experiment:

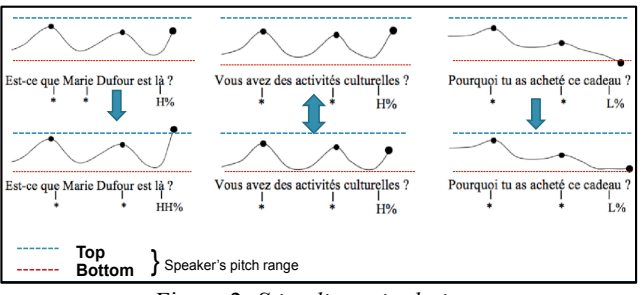

Figure 2: Stimuli manipulation.

The final syllable of each question (on which the tonal contour is realized) was composed exclusively of sonorants and mid oral vowels. Spanish questions were stressed either on the penultimate or on the final syllable. As for French wh-'insitu' questions, a noun followed the interrogative word in order for the rise related to the pitch accent to be anchored on the wh-word.

\subsection{Participants and task methodology}

As mentioned three categories of participants were set up, the native speakers being control groups and the non-native speakers the experimental group. This latter group (hence FL2) was composed of 23 native Mexican Spanish speaker aged 24.7 years on average ( $S D$ 5.59) who attended a French course at the university of Mexico. These participants were classified into two sub-groups according to their level of proficiency in L2 French: 14 and 9 students were positioned at $\mathrm{A} 2$ and $\mathrm{B} 1$ level respectively (according to the CEFR). One of the two control groups was composed of 17 native speakers of French aged of 29.5 years (SD 11.14), and the other control group (SL1) consisted of 16 native speakers of Mexican Spanish aged 32.5 years on average (SD 8.14). The FL1 and FL2 groups were tested on French stimuli, while SL1 participants were tested on Spanish stimuli.
Since the tree contours tested here are actually acceptable in both French and Spanish, without implying a specific meaning in the investigated questions, we choose a methodological procedure that allows evaluating how these differences are perceived as gradient by native and non native listeners. Therefore, we opted for a rating task methodology.

Participants were asked to read on a computer screen different discursive contexts presenting a scenario for each question. They were instructed to listen to the resynthesized questions inserted in each scenario, and to evaluate their melody within a 1 to 5 scale $(1=$ melody is inappropriate, $5=$ melody is appropriate). 66 fillers were included in the test, stimuli were randomized, and the test was presented in 4 batches to each group of participants (batches were also randomized). The test was carried out in a quiet room with an ordinary computer and high-quality headphones.

\section{Results}

Listeners' ratings were separated in four sets for the analysis, each set being associated with a question type: yes-no declarative questions, yes-no questions with an interrogative marker, wh-'fronted' questions, and wh-'in-situ' questions. In order to analyze the ratings attributed to the stimuli by the various groups of participants, and to test which differences were statistically significant, we constructed linear mixed effect models that took into account the predictor variables Contour (HH\%, H\%, L\%), Group (FL1, FL2, SL1) and random intercepts and slopes for Subjects, for each of the structures which were tested separately. The contribution of each predictor variable was assessed using model reduction and likelihood ratio tests $\left(\chi^{2}\right)$.

With regard to yes-no declaratives questions, results showed significant main effect of Contour for ratings: listeners rated $\mathrm{HH} \%$ higher than $\mathrm{H} \%(\mathrm{p}<.01)$. There was, however, no main interaction between Group and Contour for the ratings, i.e., all participants prefer extra rising tunes independently of their L1 in this question type (FL1 included). It was expected that, on the basis of the canonical rising patterns pointed in section 2, Spanish listeners would evaluate better $\mathrm{HH} \%$ than $\mathrm{H} \%$, whereas French native listeners would prefer $\mathrm{H} \%$. So, the results obtained for this question set cannot help validating the hypothesis of a difference between L2 and natives speakers: FL1 participants prefer extra-rising contours to rising ones, even if this tonal contour is not frequent in their oral productions, as well as in the canonical description of French intonation.

As for yes-no questions with a lexical or morphosyntactic marker, we found a main effect of Group interacting with the Contour for the ratings: FL2 rated rising tunes $(\mathrm{H} \%$ and $\mathrm{HH} \%$ grouped) higher than the falling ones, while FL1 did not show a clear preference $(\mathrm{p}<.0001)$. In other words, the distribution of ratings for this question set depends on the native language of listeners. In this case, the two Groups did not show a preference for either $\mathrm{H} \%$ or $\mathrm{HH} \%(\mathrm{p}>.05)$. As illustrated in Fig 3, ratings for $\mathrm{L} \%$ in yes-no questions with a marker were extremely different across the two groups. These results could be interpreted as showing that non-native listeners prefer rising tunes, even when the modality of the sentence is marked by others means. 


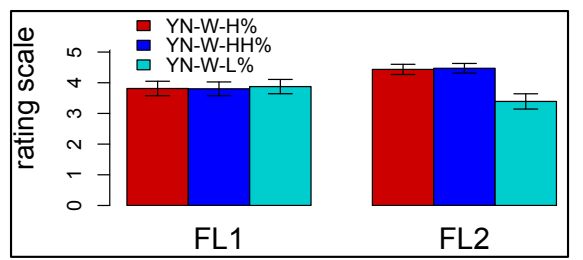

Figure 3: Ratings given to yes-no marked questions

In the set containing wh-questions with fronted wh-words, the analysis revealed that all listeners preferred rising contours ( $\mathrm{HH} \%$ and $\mathrm{H} \%$ grouped) to falling ones $(\mathrm{p}<.0001)$. When comparing ratings of Groups concerning only the $\mathrm{H} \%$ and $\mathrm{HH} \%$, it appears that there are significant differences as well: all participants rated higher $\mathrm{H} \%$ than $\mathrm{HH} \%(\mathrm{p}<.01)$. Contrary to our expectations, there is no a main effect of interaction between Group and Contour in ratings. These results revealed that all groups, independently of their linguistic background, show a preference for $\mathrm{H} \%$ in this structure. The results obtained cannot allow supporting any hypothesis. Both native and non-native speakers do show preference for tunes that they do not use so much.

An analysis carried out for wh- 'in-situ' questions showed that there is a main effect of Contour for scores: all participants prefered rising tunes $(\mathrm{H} \%$ and $\mathrm{HH} \%$ grouped) to falling ones $(\mathrm{p}<.001)$. However, an analysis modeling the interaction between Group and Contour for ratings (rising vs. falling) did not reach significance: all participants, be they French or Spanish natives, prefer rising contours than the falling ones for this question set. When we excluded the falling contours, we found a significant interaction between the Group and Rising Contours ( $\mathrm{H} \%$ vs $\mathrm{HH} \%$ ) for ratings: FL2 evaluated the extra-rising contour better than $\mathrm{H} \%$; whereas FL1 did not show any preference $(\mathrm{p}<.05)$. These differences are illustrated in figure 4:

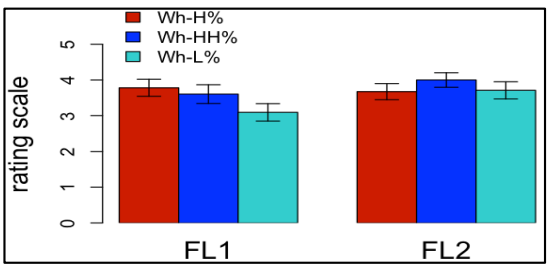

Figure 4: Ratings given to wh- 'in-situ' questions.

Finally, in order to test whether the proficiency level had an effect on the choice of contour, we carried out an analysis including all question types. Main effects were found for ratings of Contour: rising tunes $(\mathrm{H} \%$ and $\mathrm{HH} \%$ grouped $)$ received higher scores than falling ones. When comparing only ratings attributed to rising contours (excluding L\%), results showed that all learners evaluated $\mathrm{HH} \%$ higher than $\mathrm{H} \%(\mathrm{p}<.05)$. Nevertheless, no significant interaction between proficiency level and Contour on the rating choices was found. In other words, all FL2 listeners attributed ratings in the same way, despite their proficiency in L2 French.

\section{Discussion and conclusion}

In a global perspective, this study shows that all listeners, independently of their L1, rated rising contours better than falling contours when listening to yes-no and wh-questions, showing that there is a discrepancy between the patterns observed in oral productions and the perception. Regarding the scores of native listeners, the study revealed unexpected results. On the one hand, native listeners prefered rising tunes over falling tunes in questions they usually produced with falling contours (wh-questions). On the other hand, expected differences in rating concerning the form of the rising tunes $(\mathrm{H} \%$ vs. $\mathrm{HH} \%)$ were not observed in yes-no questions: FL1 listeners showed the same tendency as the other groups in rating the $\mathrm{HH} \%$ contour higher, even though they do not employ it in their oral productions. These results suggest that rising tunes are considered as a universal prototypical form for declarative questions, regardless of their phonetic form $(\mathrm{H} \%$ or $\mathrm{HH} \%$ ). In addition, rising forms are associated with all types of questions in the mind of both French and Spanish listeners, even if the contours that surface in the productions may be falling for some question types. In other words, listeners preferred rising contours because it is the form they associate with questions in their mind, independently of the fact that it does not correspond to what they produce. This explanation goes along the lines of Ohala's Frequency Code and Gussenhoven's Effort Code (see [15]).

In wh-questions, native listeners did not prefer the extra rising contour $\mathrm{HH} \%$. This could possibly result from the fact that this tune is unfamiliar to them for these question types. In addition, learners provide higher ratings for rising tunes $(\mathrm{H} \%$ and $\mathrm{HH} \%)$ associated with yes-no questions with a marker and with 'insitu' questions than native listeners do. Interestingly, in the case of wh- 'in-situ' questions, learners display a preference for the $\mathrm{HH} \%$ contour in comparison to native speakers. By and large results show that native listeners prefer rising tunes displaying a familiar or natural increase in pitch for whquestions ( $\mathrm{H} \%$ covering approx. 8 semitones like in their $\mathrm{L} 1)$, and non-native listeners actually prefer uncommon extra-rising contours ( $\mathrm{HH} \%$ increasing more than 11 semitones) when listening to L2 stimuli. This is even more so in the case of questions with a morphosyntactic form that does not exist in the learners' L1. This interesting result suggests that the use of the $\mathrm{HH} \%$ contour may be is related to the occurrence of a linguistic form that does not exist in their L1. This form could thus be seen as a default form in the case of linguistic insecurity. Further research on this issue is necessary to confirm that hypothesis and guaranty that results may not result from the task itself that asks for a kind of metalinguistic analysis.

\section{Acknowledgements}

This study was supported by a doctoral grant from CONACYT (Mexico) and by the ANR Labex EFL "Empirical Foundations in Linguistics" (workpackage PPC 4: The acquisition of phonetics, phonology and prosody in French and English as an L2).

\section{References}

[1] Mennen, I. "Bi-directional interference in the intonation of Dutch speakers of Greek", Journal of Phonetics 32, 543-563, 2004.

[2] Mennen, I. "Phonological and phonetic influences in non-native intonation", in J. Trouvain, \& U. Gut [Eds.], Non-native Prosody: Phonetic Descriptions and Teaching Practice (Nichtmuttersprachliche Prosodie: phonetische Beschreibungen und didaktische Praxis), Mouton De Gruyter, 53-76, 2007. 
[3] Jilka, M, "Different manifestations and perceptions of foreing accent in intonation", in J. Trouvain, and U. Gut [Eds], NonNative Prosody. Phonetic Description and Teaching Practice, 7796, Mouton de Gruyter, 2007.

[4] Santiago, F. and Delais-Roussarie, E., "The acquisition of Question Intonation by Mexican Spanish Learners of French", in Prosody and Language in contact: L2 acquisition, attrition, languages in multilingual situations, Springer Verlag, to appear.

[5] Santiago, F. \& Delais-Roussarie, E. "La prosodie des énoncé interrogatifs en français L2", in L. Besacier, B. Lecouteux and G. Sérasset [Eds], Proceedings of Journée d'Études sur la Parole, JEP 2012, 265-272, 2012

[6] De la Mota, C., Butragueño, P. and Prieto, P. "Mexican Spanish Intonation", in P. Prieto, and P. Roseano [Eds], Transcription of Intonation of the Spanish Language, 319-350, Lincom Europa, 2010.

[7] Sosa, J., La entonación del español: su estructura fónica, variabilidad y dialectología, Cátedra, 1999.

[8] Sosa, J., "Wh-questions in Spanish: Meanings and Configuration Variability", Catalan Journal of Linguistics, 2: 229-247, 2003.

[9] Grundstrom, A. "L'intonation des questions en français standard", in A Grundstrom and P. Léon, Interrogation et Intonation, 19-51, Klincksieck, 1973.

[10] Di Cristo, A., "Intonation in French", in H. Daniel J, and D. Albert [Eds], Intonation Systems: A Survey of twenty languages, 195-218, Cambridge University Press, 1998.

[11] Beyssade, C., Delais-Roussarie, E., and Marandin, J.-M., "The prosody of interrogatives in French", Nouveaux cahiers de linguistique française, 28: 163-175, 2007.

[12] Déprez, V., Syrett, K., and Kawahara, S., "The interaction of syntax, prosody, and discourse in licensing French wh-in-situ questions", Lingua, 124: 4-19, 2012.

[13] Quilis, A., Tratado de fonología y fonética españolas, Gredos, 1993.

[14] Horgues, C. Prosodie de l'accent français en anglais et perception par des auditeurs anglophones. Unpublished $\mathrm{PhD}$ Thesis, Université Paris Diderot, 2010

[15] Gussenhoven, C, The Phonology of Tone and Intonation. Cambridge, Cambridge University Press, 2004. 